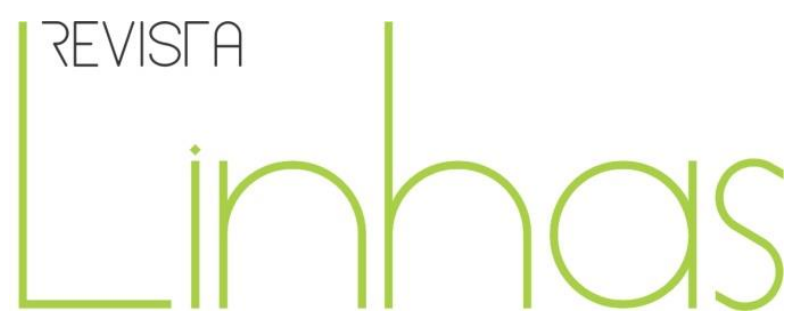

\title{
Como as imagens nos educam para os gêneros e as sexualidades? - Cultura visual e formação docente
}

\begin{abstract}
Resumo
Este texto traz para discussão os resultados de uma pesquisa realizada no encontro entre a formação docente e a cultura visual, interessada na produção e relação das imagens com a constituição dos sujeitos na contemporaneidade. Como as imagens nos educam para os gêneros e as sexualidades? A partir dos questionários e do grupo focal com os graduandos e graduandas dos cursos de Licenciatura em Pedagogia e História, foi possível discutir e problematizar a relação entre a Cultura Visual, a formação docente, os currículos e a construção das identidades de gênero e sexuais. Um campo problemático construído a partir das questões com as imagens e seus contextos de formação e diretamente ligado aos currículos de História e Pedagogia. Neste sentido, nos aproximamos da abordagem teórica pós-estruturalista, especialmente no que se refere às contribuições de Foucault a respeito das relações podersaber, governo dos corpos e importância da linguagem como construção histórica, definidora de comportamentos, de percepções e de condutas, enfim, ações e pensamentos que nos organizam nas nossas ações nas salas de aula e nas relações com os conhecimentos, com o currículo como escolha do que deve fazer parte, ou não, das nossas aulas.
\end{abstract}

Palavras-chave: Cultura Visual; Professores - Formação; Currículos; Educação; Gênero.

\author{
Anderson Ferrari \\ Universidade Federal de Juiz de \\ Fora - UFJF - MG/Brasil \\ aferrari13@globo.com
}

Roney Polato de Castro

Universidade Federal de Juiz de

Fora - UFJF - MG/Brasil roneypolato@gmail.com

\footnotetext{
Para citar este artigo:

FERRARI, Anderson; CASTRO, Roney Polato de. Como as imagens nos educam para os gêneros e as sexualidades? - Cultura visual e formação docente. Revista Linhas. Florianópolis, v. 17, n. 34, p. 08-27, maio/ago. 2016.
}

DOI: $10.5965 / 1984723817342016008$

http://dx.doi.org/10.5965/1984723817342016008 


\title{
As the images educate us to the genders and sexualities? - Visual culture and teacher education
}

\begin{abstract}
This text brings to discussion the results of a survey conducted in the intersection between teacher education and visual culture, interested in the production and the relations of images with the constitution of the subject in contemporary times. How do images educate us to genders and sexualities? Through the questionnaires and focus group with undergraduate students from the courses in pedagogy and history, it was possible to discuss the relationship between Visual Culture, Teacher Education, Curriculum and the construction of gender and sexual identities. A problematic field built from the issues with images and their educational contexts and directly linked to the History and Pedagogy curricula. In that sense, this article draws near the post-structuralist theoretical approach, especially with regard to the contributions of Foucault on power-knowledge relations, government bodies and the importance of language as a historical construction, defining behaviors, perceptions and conducts, ultimately, actions and thoughts that organize us in our actions in the classroom, the relations with knowledge and the curriculum as a choice of what should or should not be made part of our classes.
\end{abstract}

Keywords: Visual Culture; Teachers - Education; Curriculum; Education; Gender. 


\section{Introdução}

Este texto se produziu a partir de uma pesquisa que vem sendo realizada desde 2014, e que busca problematizar a formação docente de estudantes dos cursos de Pedagogia e História, sobretudo no que diz respeito à relação entre cultura visual, formação docente, currículo e educação.

Numa pesquisa realizada anteriormente, com adolescentes de quatro escolas em Juiz de Fora (MG), um dado se destacou: a presença constante de artefatos que são utilizados no cotidiano escolar para produção de imagens, tais como o computador e o celular. Ao mesmo tempo em que diziam produzir cotidianamente imagens de si e do grupo de amigos/as como uma maneira de produzir-se a si mesmos/as, as/os adolescentes também mostraram um desprendimento imediato de tais produções, ou seja, muitas dessas imagens eram apagadas no momento subsequente para dar lugar a outras, num jogo entre memória e esquecimento que dizia a respeito do movimento de constituição dos sujeitos no contexto atual. Tomando esse dado como importante para entender nossas relações com a sociedade imagética, queremos considerá-lo como algo que impacta o campo da Educação, sobretudo a discussão sobre currículo e formação docente, visto que trata da nossa relação com o que chamamos de 'realidade'. São processos que estão ocorrendo em meio às relações de ensino-aprendizagem, escolhas de temáticas, vinculação professores/professoras/alunos/alunas, que em última análise falam do interesse pela escola, mesmo que, primordialmente, como espaço de socialização. Mais do que isso, as/os adolescentes abordam a produção de imagens na sala de aula e em outros espaços de circulação nas escolas, sem que os professores e professoras se dessem conta ou mesmo percebessem essa vinculação. Por sua vez, os/as adolescentes pesquisados/as não reconheciam qualquer atividade com as imagens realizada pelas escolas, com exceção da escola pública federal, na qual constava no seu currículo de Artes um trabalho com cinema.

Desta forma, a pesquisa colocava um desafio para as escolas (e para as/os professoras/es), que passa pela formação docente e o currículo, entendendo que a sociedade imagética nos instiga a um trabalho com a cultura visual como um campo de saber e poder, de produção de sujeitos. Junto ao nosso trabalho, com os cursos de Licenciatura em História e em Pedagogia, essas questões de pesquisa nos conduzem a 
pensar a articulação entre estudantes de graduação em História e Pedagogia, formação docente e currículo nas suas diferentes relações com as imagens e o saber, sejam elas voltadas para o conhecimento científico ou aquelas que estão direcionadas à leitura, elaboração, entendimento e relação com as imagens. Por tudo isso, nos interessa problematizar as apropriações de estudantes das Licenciaturas de História e da Pedagogia da UFJF (Universidade Federal de Juiz de Fora) em torno do trabalho com as imagens. Que desafios e potencialidades identificamos para o trabalho com as imagens?

$\mathrm{Na}$ busca por possibilidades de respostas a essa questão, a ideia é colocar sob suspeita os modos como essas/es estudantes vão se constituindo como sujeitos, algo que antecede a sua entrada na UFJF, para questionar como vão se tornando professores e professoras. Processos de constituição que atravessam e são atravessados por outras formas de estar no mundo, trazendo desdobramentos para pensar posições de sujeito em meio à realidade tecnológica que nos constitui, que estão presentes nas escolas, que tratam da relação com as salas de aula, com os saberes, os conhecimentos, a disciplina, num processo de mão dupla que nos coloca o desafio de discutir a formação docente e o currículo. Sendo assim, aliamos à discussão sobre a cultura visual com àquelas que dizem respeito ao campo das sexualidades e das relações de gênero, uma vez que nossa compreensão é a de que esses campos são atravessados pelo movimento que envolve as imagens, os currículos dos cursos de História e Pedagogia, a formação docente como elementos da constituição de sujeitos. O trabalho com educação está diretamente implicado nas relações de gênero e sexualidades, de maneira que nos interessa, por meio da pesquisa anteriormente citada, buscar interlocuções entre esses campos, problematizando as relações das/os estudantes de Licenciatura em História e Pedagogia com as sexualidades e os gêneros, a partir do que pode se considerar como 'ausente' ou 'presente' nos currículos desses cursos.

A pesquisa que tomamos como partida para as análises deste artigo desenvolve-se a partir de dois instrumentos: questionários qualitativos, com questões abertas, e grupos focais, ambos dirigidos a estudantes dos cursos de História e Pedagogia da UFJF. O contato com essas/es estudantes se deu a partir de sua inserção nas disciplinas em que atuamos nesses cursos. Assim, assumimos que a pesquisa não é aleatória, mas está intimamente relacionada ao trabalho que desenvolvemos na Faculdade de Educação da 
UFJF, aliando ensino, pesquisa e extensão nas temáticas de relações de gênero, sexualidades, cultura visual, formação docente e educação em História. O questionário foi respondido por cinquenta estudantes e se dividiu em duas partes: questões sobre a formação antes da graduação e questões sobre a formação na graduação. Para este trabalho em especial, trabalharemos somente com os dados produzidos a partir das respostas de estudantes do curso de Licenciatura em História, focando em duas questões que diziam do trabalho das escolas e da universidade com as relações de gênero e sexualidades. São elas: “Em algum momento os seus professores de História dos Ensinos Fundamental e Médio vincularam o trabalho da História com as relações de gênero e sexualidade? Em que momento?" e "Em algum momento os seus professores de História da graduação vincularam o trabalho da História com as relações de gênero e sexualidade? Em que momento?". Trabalhando com a perspectiva foucaultiana, estamos considerando que somos seres discursivos, de maneira que as nossas palavras nos constituem. Nesse sentido, a formação não diz respeito apenas ao/à futuro/a professor/a de História, mas também nos mostra o investimento num tipo de sujeito. Para sua melhor organização, o artigo será dividido em três partes. A primeira dedicada à discussão teórica entre ensino de História, relações de gênero e sexualidade e cultura visual. A segunda e terceira partes serão construídas com o foco nas respostas às duas questões selecionadas.

\section{Ensino de História, Cultura Visual, Relações de Gênero e Sexualidades}

Estabelecer relações entre Cultura Visual, Ensino de História, Relações de Gênero e Sexualidades é algo desafiador, embora sejam campos de estudos que se atravessam, sobretudo se pensarmos o cotidiano da sala de aula e as potencialidades que representam para a História o trabalho com as imagens, bem como para a leitura das imagens o olhar da História. Segundo Dikovitskaya (2005) Cultura Visual é tudo aquilo que diz respeito à construção visual podendo ser tanto uma obra de arte quanto propagandas veiculadas na televisão, enfim, o que compõe as imagens do cotidiano. Não se constituindo enquanto disciplina, configura-se como uma área de investigação cada vez mais incluída nos currículos, seja das universidades ou mesmo das escolas, tendo como preocupação central a imagem, entendida como fundamental nos processos de construção dos significados nos contextos culturais. As mudanças ocorridas desde a 
década de 1970 e, mais fortemente a partir dos anos 1980, com a influência da televisão e dos novos meios de comunicação na vida de brasileiros e brasileiras (como, por exemplo, o uso do vídeo), fizeram com que professores/as de História iniciassem discussões e experiências no ensino em articulação com esses 'novos' instrumentos e com recursos didáticos mais antigos que foram ressignificados (COSTA e OLIVEIRA, 2007). Contemporâneos a essas modificações, os estudos de Cultura Visual emergem também na década de 1980,

no âmbito de um debate que cruza e transcende diferentes disciplinas e produz uma relação entre saberes vinculados à história da arte, aos estudos dos meios, aos estudos cinematográficos, à lingüística e à literatura comparada com as teorias pós-estruturalistas e os estudos culturais. (HERNANDEZ, 2007, p. 21)

No Brasil, a produção em torno do Ensino de História pode ser classificada como ampla e diversificada. Exemplos disso são os fóruns de debates específicos para essa área, além da constituição de um grupo de pesquisadoras e pesquisadores dedicadas/os às diferentes temáticas que envolvem esse campo: currículo, formação de professores/as de História, livro didático, História e novas tecnologias, entre outras. Distanciando-se de uma tradição das universidades brasileiras, o ensino de História, que até a década de 1960 não se constituía como área de formação, tampouco como objeto de estudo e de investigação, foi pouco a pouco ampliando sua área de atuação. Da crítica aos livros didáticos, a incorporação e discussão metodológica dos novos artefatos culturais na sala de aula, as reformas curriculares e o olhar atento ao que ocorria como experiências nas escolas deram origem a um campo de conhecimento inovador e crítico (COSTA e OLIVEIRA, 2007).

O que pretendemos discutir com essa breve história e com a construção conceitual da Cultura Visual e do ensino de História, é que ambos são frutos de transformações ocorridas a partir da década de 1980, período de expansão da televisão no Brasil e das novas tecnologias associadas a imagens. Mas, também um período importante para as discussões e construções do campo das relações de gênero e sexualidades. Foi no final da década de 1970 e início de 1980, que os movimentos 
feministas e os primeiros grupos gays se organizaram. Dois movimentos que colocavam na pauta de discussão alguns aspectos que constituíam a sociedade brasileira, tais como o machismo, o preconceito, a discriminação, a desigualdade entre homens e mulheres e a violência que atingia sobremaneira alguns grupos sociais. Os grupos gays em especial, se organizavam com a ânsia de desconstruir as imagens negativas das homossexualidades e de construir imagens mais positivas. A escola e os meios de comunicação eram setores que faziam parte desses processos, de maneira que problematizar as relações de gênero e sexualidades que tínhamos, e promover novas formas de ser e estar no mundo passava pelo investimento na formação de professoras e professores e numa política de novas imagens nos meios de comunicação.

Nesse sentido, nos parece importante perceber esses campos a partir de um ponto de convergência que é o entendimento das suas práticas, discursos, discussões e teorizações como artefatos de linguagem, produções culturais e históricas, enfim, como construções e não como verdades. Cultura Visual e ensino de História seriam parte do que chamamos de Ciências Humanas e Sociais, entendidas como instâncias discursivas culturais, a partir das quais se produzem significados sobre o que chamamos de 'realidade'. Da mesma forma, as relações de gênero (SCOTT, 1995) e as sexualidades falam deste processo de construção, afetando e sendo afetadas pelas Ciências Humanas e Sociais.

A relevância das representações visuais e das práticas culturais para a construção das subjetividades, o papel dessas manifestações para o sentido de infância e juventude, as novas necessidades de educação diante desses movimentos e a importância do 'visual' e do 'olhar' na nossa sociedade nos chamam também a 'olhar' a sala de aula e nosso trabalho como docentes a partir de outro lugar. Nesse sentido, o ensino de História no Brasil é um campo que nos ajuda a pensar essas transformações, a produção de conhecimento e sua vinculação com a educação e, para além dessas relações, nos possibilita problematizar essas ações, numa aproximação com a perspectiva foucaultiana. Desse modo, pensamos o ensino de História e sua vinculação com a contemporaneidade sob inspiração desse autor e de sua "caixa de ferramentas", especificamente em relação ao conceito de História, buscando aproximações com a cultura visual. 
Michel Foucault não era um historiador e negava esse enquadramento. No entanto, não é difícil encontrar referências à História em sua obra. Não somente nos títulos - História da Loucura, História das sexualidades - o que já nos remete à sua vinculação com esse campo de conhecimento, como também na própria condução de suas construções. Assumindo-se como "pirotécnico", estava interessado nas explosões, nos efeitos das suas palavras e na infidelidade que elas poderiam resultar. Dizendo de outra forma, que sua escrita e seu pensamento fossem capazes de fazer pensar para além deles, servissem de inspiração para algo diferente e, como os fogos de artifícios que se apagassem depois de explodir, negando com isso um sentido de verdade absoluta.

Por isso, um conceito que parece importante para a discussão do ensino de História é o de "problematização".

Dar um passo para trás é, ao mesmo tempo, uma liberdade para Foucault. É a liberdade de separar-se do que se faz, é o movimento pelo qual alguém se separa do que se faz, de forma a estabelecê-lo como um objeto de pensamento e a refletir sobre ele como um problema... Questionar significados, condições e metas é, ao mesmo tempo, liberdade em relação ao que se faz. É tratar o objeto de pensamento como um problema. Um sistema de pensamento seria uma história de problemas ou uma problematização. Envolveria o desenvolvimento de um conjunto de condições nas quais possíveis respostas pudessem ser propostas. Mas não se apresentaria como uma solução ou resposta. (MARSHALL, 2008, p. 31)

Problematização como uma prática de olhar para frente sem, no entanto, dar soluções, mas desconfiar do que está dado, naturalizado, ou seja, transformar em problema o que não nos chama atenção. Investir mais nas perguntas do que nas repostas. Sendo assim, o que interessa para Foucault, quando trabalha na articulação com a História, são as descontinuidades, as rupturas. Descontinuidades que, ao tomarem forma, denunciam as continuidades. Num artigo intitulado "Nietzsche, a genealogia e a história", Foucault (1998) utiliza-se dos conceitos nietzschianos para mostrar como o Ocidente moderno inventa a História, acusada de ascética, uma vez que busca encontrar no passado o momento fundante de sua unidade, de sua identidade. Dessa forma, a História foi o elemento ordenador que deu sentido de coesão aos povos e nações, contribuindo 
para fazer surgir o ideal ascético do historiador que, seguido pelo discurso científico, forneceram à História os sentidos de objetividade, Ciência e verdade. Nessa lógica de raciocínio, o historiador ${ }^{1}$ era aquele que apenas narrava o ocorrido, fornecendo as origens dos fatos e o próprio fato em si.

O argumento que apresentamos é o de que tanto a visão de História proposta por Foucault, quanto o que os estudos de Cultura Visual propõem é que possamos inventar novas subjetividades, sobretudo com base nas resistências, transgressões e liberdades, rompendo com o dualismo ver/falar, falar/escutar, professor/a/aluno/a, razão/emoção. 0 sentido de trabalhar imagens e conhecimentos históricos estaria nas possibilidades que esses campos de problematização abrem para a compreensão do social e cultural que cada um de nós fazemos parte.

\section{Gêneros e sexualidades na escola (antes da graduação)}

Relações de gênero, sexualidades e educação: um campo de estudos que vem se consolidando no Brasil, a partir de inúmeras pesquisas, práticas de extensão e formação docente e atividades de ensino nas escolas e universidades. Um campo que é constituído pelo atravessamento de outros campos de conhecimento (Ciências Sociais, História, Filosofia, Pedagogia, Psicologia, entre outros). As escolas e suas práticas de educação para sexualidade e relações de gênero têm sido o principal foco das pesquisas e ações extensionistas desenvolvidas no campo, porém, sem desconsiderar que os processos educativos se desenvolvem por meio de outras pedagogias, não escolares, produzindo sujeitos de sexualidade e gênero através dos programas de TV, propagandas, revistas, jornais, músicas, brinquedos, obras de arte, entre tantos outros. Nesse âmbito, as imagens vêm recebendo uma atenção especial, pois numa sociedade imagética, precisamos considerar os processos de constituição de sujeitos, sexualidades e gêneros deflagrados na relação com as imagens. Em especial, as imagens se tornaram processos políticos, na medida em que visibilizam sujeitos, saberes e práticas antes invisibilizados.

Estudiosas/os do campo apontam, em seus escritos, para certas características das práticas pedagógicas ligadas aos gêneros e sexualidades (LOURO, 2007; FURLANI, 2007),

\footnotetext{
${ }^{1}$ Optamos pela escrita no masculino, entendendo que nesse contexto de produção da História era a visão masculina que prevalecia, tanto na sua produção quanto nas representações que essa História produzia.
} 
tais como uma associação da sexualidade com aspectos biológicos e a naturalização de 'papéis' binários masculinos e femininos, entre outras. É importante destacar que, embora muitas instituições escolares e profissionais afirmem desconhecer como as questões de sexualidades e gêneros aparecem ou neguem sua existência, essa educação vem sendo promovida. Ou seja, a educação para as sexualidades e para as relações de gênero não acontece apenas nas práticas que a isso se destinam, mas está presente nos mecanismos de constituição de sujeitos, nas intervenções promovidas sobre os corpos, nas proibições, nas normas estabelecidas, nas relações interpessoais, nos materiais didáticos, nas imagens que circulam e são produzidas nas escolas. Processos educativos sutis e naturalizados que são produzidos e reproduzidos nas instituições escolares, frequentemente reforçando normas sociais de conduta, preconceitos e violências.

Do universo de cinquenta questionários respondidos em nossa pesquisa, somente cinco estudantes identificaram algum trabalho com as relações de gênero e com as sexualidades enquanto estavam na escola. O restante respondeu à questão "Em algum momento os seus professores de História dos Ensinos Fundamental e Médio vincularam o trabalho da História com as relações de gênero e sexualidade?" de maneira negativa. Não somente não reconheciam este trabalho, mas não detalhavam as respostas, se limitando a utilizar expressões curtas, como "não”, "nem pensar”, "não que eu me lembre”, "dentro de sala de aula nunca houve esta discussão". Três das respostas negativas desenvolveram mais seus apontamentos o que nos permite vislumbrar o espaço destinado às discussões de gênero e sexualidades nas escolas e que reforça os achados em outras pesquisas que insistem em afirmar que a escola não está preparada para este trabalho e que, portanto, ele não está presente nas salas de aula. Dizem eles:

Não que eu me lembre. Estudei em um colégio muito conservador.

Nunca. Só fui ouvir falar disso na Universidade. Sexualidade era domínio da Biologia.

Esse assunto pouco era abordado, era tido como um tabu em sala de aula. 
Um colégio conservador, o domínio da Biologia, um tabu. Três aspectos que definem o trabalho com as relações de gênero e sexualidades nas escolas. A escrita dessas/as estudantes faz pensar que o trabalho com essas questões e as diferentes posturas diante delas estarão vinculados ao tipo de escola a que nos referimos - uma escola mais conservadora, mais de vanguarda, confessional, laica, privada, pública. Os tipos de escolas em que circulamos definem o tipo de trabalho que podemos exercer. Embora as escritas nos encaminhem para uma negatividade - "Nunca", "Não" pensamos que há sempre possibilidades de resistências, de buscar brechas para a discussão, sobretudo tomando a perspectiva de Joan Scott (1995), que argumenta que as construções de gênero estão presentes nos múltiplos contextos em que habitamos. 0 ensino de História é um desses contextos, que trabalha o tempo todo com as construções de gênero. Se olharmos atentamente para os livros didáticos de História (presença marcante nas aulas) podemos perceber que há uma História de Homens (as mulheres pouco aparecem), Brancos (os negros são tratados somente até o fim da escravidão e somente como escravos), Católicos (outras religiões quando aparecem estão quase sempre vinculadas a um aspecto folclórico) e Heterossexuais (outras formas de sexualidades não são apresentadas). Os professores e professoras de História trabalham cotidianamente com as construções de gêneros e sexualidades, produzindo em suas aulas os lugares de homens e mulheres em que o sujeito histórico é o homem. Podemos dizer, desse modo, que o "Nunca" e o "Não que eu me lembre" são escritas que remetem a uma experiência com o ensino de História, na qual a visibilidade das construções das relações de gênero e sexualidades não foi possível.

Outro espaço definido como “domínio" das relações de gênero e sexualidades é a Biologia. Sob um viés biológico, podemos argumentar que esses temas aparecem como parte do conteúdo programático da disciplina. Está nos livros didáticos, nas imagens dos corpos, dos "sistemas reprodutores", bem como nas descrições dos ciclos e processos reprodutivos dos seres vivos. Estão presentes também nas “sessões especiais" e nos "box" de textos e notícias que abordam a gravidez e as doenças sexualmente transmissíveis, assim como os métodos de prevenção. Algo que pode se configurar como um incômodo às/aos professoras/es que não se sentem "à vontade" ou não desejam discutir essas temáticas. A "presença” desses elementos nos materiais didáticos e a 
tradição curricular da disciplina Biologia em ter que apresentar conteúdos relativos à chamada "educação sexual", quase obriga o/a professor/a a tratar dessas temáticas. A questão é que o tratamento muitas vezes fica no biológico. A escrita das/os estudantes no questionário diz de um "domínio" - sexualidades e relações de gênero dominadas pelo biológico, centradas na discussão dos hormônios, das fases da vida, das modificações corporais ocasionadas pela puberdade, sem um olhar para os desejos, as atrações, sem uma vinculação com o social, com as experiências das sexualidades e das relações de gênero.

Trabalhar com essas temáticas na História é arriscar no óbvio, ou seja, parece ser óbvio esse trabalho na Biologia e não na História. Assim, ao trabalhar sexualidades e relações de gênero nas aulas de História, em uma disciplina em que os alunos e alunas não esperam, conseguimos estabelecer outras relações e ampliar as possibilidades de discussão. Estamos argumentando que esse trabalho possibilita exercitar alguns dos sentidos fundamentais do Ensino de História e da apresentação de imagens, sejam elas de livro didático, de televisão ou de cinema: a curiosidade, a dúvida, a transformação em 'problema' do que estamos vendo e aprendendo. Nesse sentido, é possível provocar nas/os alunas e alunos que tragam outras informações, que falem sobre as suas experiências de leitura de mundo. Dessa forma, é possível problematizar o que é entendido como "natural" - o amor, as relações afetivas entre homem e mulher, os "papéis" de gênero, as sexualidades -, enfim, a partir das imagens e que servem para outras situações de ensino-aprendizagem, num processo de educação mais voltado para as subjetividades do que para os conteúdos ditos 'formais'. O que podemos pensar de nós, de nossas sexualidades e gêneros, e o que podemos ler de nosso mundo a partir desse ponto de partida das imagens? Como a História nos abre novas possibilidades de leitura do que está no livro e do meu mundo em si?

Com nossos argumentos não queremos insinuar que nada se faz nas escolas. Não queremos ficar no "Nunca" e no "Não". Argumentamos que as escolas trabalham com as relações de gênero e sexualidades, mas isso não significa um trabalho consciente, deliberado, organizado. As relações de gênero e sexualidades estão presentes cotidianamente nas salas de aula, seja nas relações com os alunos e alunas, nas piadas, apelidos, brincadeiras, atrações, agressões, aproximações, enfim, uma infinidade de 
possibilidades que também passam pela relação com as disciplinas e conteúdos. Nesse sentido, encontramos escritas que falam de um trabalho organizado pelos professores e professoras de História:

Assunto tocado muito superficialmente. Apenas em momentos específicos da disciplina como na Idade Média e sua repressão sexual.

Sim, esse tipo de trabalho só tive no ensino fundamental.

Somente com a reprodução de modelos. Havia um programa na escola, se não me engano era um programa do Estado sobre educação sexual e sexualidade aberto para inscrições.

Lembro de um trabalho interdisciplinar com a temática da beleza que buscava trabalhar com o gênero, mas teve como resultado apenas 0 olhar exterior da temática.

Em poucos momentos. Só me recordo de ter acesso a esta temática no terceiro ano do Ensino Médio, que apenas trabalhou de forma bem restrita a emergência do movimento feminista. Acredito que esta pouca ênfase se deu ao fato do colégio estar vinculado a uma forte tradição religiosa.

As relações de gênero e sexualidade têm história (FOUCAULT, 1988) e, vincular essa história aos sentidos que essas relações adquirem na nossa sociedade, é uma maneira de entender como foram sendo fixadas as relações entre os gêneros e sexualidades. O trabalho com a História das palavras e, portanto, com a história das sexualidades e dos gêneros é ressaltar a importância da História e das escolas em descobrir diversas possibilidades de ser e estar no mundo nas diferentes sociedades e períodos e, mais do que isso, é problematizar os sentidos dessas relações e como elas funcionam na manutenção da ordem social. Esse trabalho nos possibilita pensar o papel da História na construção dos sujeitos históricos, como críticos e capazes de modificar suas histórias. Em todas as respostas positivas não há nenhum aluno ou aluna que foi capaz de identificar os objetivos do trabalho na História, de forma que parecem que mesmo o reconhecendo, não conseguiram perceber a importância e finalidade dele.

As escritas das/os estudantes remetem-se a memórias que contêm lembranças e esquecimentos. O que se lembra? Rastros de trabalhos e abordagens das sexualidades e 
das relações de gênero no trabalho de professoras e professores de História. Uma escrita que trata de limitações - "assunto tocado superficialmente", "só tive no ensino fundamental", "somente com a reprodução de modelos", "apenas o olhar exterior da temática", "em poucos momentos", "apenas trabalhou de forma bem restrita”. Essas/es estudantes produzem escritas que remetem às experiências vividas, que tomam outros significados no presente. As limitações aparecem a partir de compreensões que vêm sendo construídas na formação universitária. Limitações que podem ser pensadas como brechas, como resistências, como microliberdades articuladas nos cotidianos escolares, nos fluxos de forças que compõem esses cotidianos. Uma escrita que poderia ser lida como "apesar das limitações, algo aconteceu". Algo acontece. Relações de gênero e sexualidades estão nas relações, nos corpos, nas experiências que circulam pelas escolas. As escritas das/os estudantes nos fazem pensar nos modos como essas questões aparecem no ensino de História e nas possibilidades de remexer as noções tradicionais de conhecimento e de conteúdos válidos, legitimados nas salas de aula. Algo que nos faz pensar nas rachaduras em currículos que se enchem de experiências subjetivas das/os estudantes, que se enchem com as curiosidades, desejos, saberes e eróticas que desafiam as limitações e passam a movimentar as salas de aula e o ensino de História.

\section{Gêneros e sexualidades na graduação: a formação inicial em questão}

Qual a importância de olhar para o processo de formação que vai da escola à graduação? Autores como Tardif (2000) e Arroyo (2000) argumentam que nos constituímos professores e professoras antes mesmo de entrar na graduação. Isso porque vivenciamos a escola por longo tempo e assim vamos construindo modos de ser professor/a. A questão é que nossas Licenciaturas, muitas vezes, são extremamente conteudistas e se esquecem de colocar sob suspeita o modelo de escola, de educação e de professor/a que temos. Quando os alunos e alunas de História afirmam não reconhecer o trabalho dos/as professores/as de História que tiveram nos ensinos Fundamental e Médio estão, em última análise, falando da formação desses/as professores/as. Parece que estamos diante de dois quadros. Por um lado, os professores e professoras não investem na relação entre ensino-aprendizagem de História, relações de gênero e sexualidades, mesmo que todo o processo de ensino-aprendizagem esteja 
atravessado por questões de gênero e sexualidade. Por outro lado, tampouco reconhecem que fazem um trabalho atravessado por concepções de gêneros e sexualidades, na medida em que trabalham os conteúdos de História.

Esse quadro parece se repetir na graduação. Somente oito estudantes responderam que vivenciaram algum momento na graduação em que as professoras e professores trabalharam questões relativas aos gêneros e sexualidades:

Sim, no momento em que os mesmos possibilitaram através de suas aulas expositivas uma ampla discussão sobre o tema abordado, fazendo também a análise de imagens que é muito presente no curso de História.

No primeiro semestre com a disciplina de História e interdisciplinaridade.

Sim. Na importância da manutenção dos direitos de todas as pessoas, sem restrições à sexualidade e gênero.

Alguns textos sobre feminismo e mulheres na História, de forma pontual. Os grupos de pesquisa sempre são os grandes espaços de discussão, produção e criação. Se forem esperar iniciativas do Departamento de História, esperaremos sentados.

Os momentos mais observados foram nas obras históricas e sua demonstração da sexualidade do período e também em alguns momentos em uma temática mais atual em referência com algum acontecimento histórico.

É raro este contato entre História, Gênero e departamento. Quando há, o enfoque é dado somente aos feminismos.

Ao tratarem da expressão da mulher, principalmente na contemporaneidade da proposta feminista.

As escritas dessas/es estudantes nos conduzem aos desafios da formação inicial, que tratam de uma perspectiva teórico-metodológica. Escritas que anunciam uma formação que se encaminha para pensar relações de gênero e sexualidades. Ao mesmo tempo, as escritas denunciam certos modos de produção das experiências históricas de gênero. São momentos pontuais, em geral provocados por docentes cujo investimento pessoal de pesquisa e discussão é para as temáticas de relações de gênero, feminismos, sexualidades, que tratam de rupturas com as histórias construídas. Parece-nos que a 
formação inicial em História ainda investe no distanciamento entre experiências masculinas e femininas, desenvolvendo uma história 'masculina', na qual o homem é o sujeito histórico. Uma história que reserva poucos momentos em que as mulheres são alçadas a esta categoria, quase como uma exceção. As escritas falam das proposições feministas que perturbam esse modo de fazer história, vinculadas a algumas disciplinas, grupos de pesquisa ou temas específicos discutidos em algum momento do curso. Escritas que anunciam relações de poder e outros distanciamentos no que tange ao campo de conhecimento da História, às conexões entre história passada e história presente, ao campo de conhecimento das relações de gênero e à proposta de formação constituída no Departamento de História.

Outra escrita nos propiciou relacionar a formação na escola e a formação inicial, pensando nas limitações apontadas pelas escritas anteriormente citadas. Colocar sob interrogação a formação na graduação fez com que uma estudante produzisse a seguinte escrita:

Nunca vincularam e gostaria muito que fosse mais divulgado palestras e livros sobre o tema por achar que temos uma formação ainda engessada. Não formamos com um conhecimento para os desafios e aprendizados do dia a dia, somos formados para passar conteúdo somente.

Formar para os desafios e aprendizados do dia a dia. Formar para as relações de gênero e sexualidades. A estudante parece vincular esses projetos formativos, ao mesmo tempo em que as distingue de uma formação "ainda engessada", associada ao "passar conteúdo". Questões que surgem da escrita: que formação para os desafios e aprendizados do dia a dia? Que conteúdos nessa formação? Entre palestras e salas de aula, entre livros e cotidianos escolares, produz-se uma formação em História que mais engessa do que movimenta as ideias.

Neste quadro, a possibilidade de continuidade entre a falta de discussão nas escolas e a formação inicial está colocada. A relação entre as instâncias é atravessada por uma aparente ausência nas discussões de temas ligados às relações de gênero e sexualidades. Notamos também, a partir da escrita da estudante e de outras/os, as 
dificuldades em reconhecer que os conteúdos de História (e de outras disciplinas) são constituídos por esses temas. Pensar nos modos como a História Ocidental se construiu, por meio de uma perspectiva masculina, heterossexual, branca, cristã é pensar no lugar das mulheres enquanto produtoras dessa História. Ao mesmo tempo, pensar nos temas que a História aborda, na formação inicial e nas escolas, é também pensar que as relações de gênero e sexualidades atravessam esses temas, constituem as histórias, organizam as distintas sociedades. A formação, talvez, não tenha investido nessas relações, de modo que as professoras e professores nas escolas parecem não conseguir vislumbrá-las. Nesse sentido, a preocupação da estudante com "os desafios e aprendizados do dia a dia" é também o anúncio das possibilidades dessa formação. Na escola, discutir a presença de homens brancos heterossexuais como protagonistas implica pensar na ausência das mulheres, dos/as negros/as e das pessoas não heterossexuais nos conteúdos e nos materiais didáticos. Ou na presença "estereotipada" dessas personagens, como elementos pouco significativos ou relegados a lugares subalternos. Na análise dos questionários, identificamos respostas que anunciam a universidade como instância que também vem se dedicando a abordar o trabalho com as relações de gênero e sexualidades. Identificamos, por exemplo, que esse trabalho é realizado na Faculdade de Educação:

Me lembro bem pouco, mas fiz uma matéria na educação em que o curso falava bastante sobre a sexualidade e gêneros principalmente entre crianças e escola.

Sim, a professora Maria da educação, em Seminário escolar.

Este assunto somente foi abordado nas matérias da educação, nas quais tratamos o tema de forma crítica e com uma visão de professores sobre o assunto.

Tensões: formação inicial no curso de História e formação inicial vivida na Faculdade de Educação. Formações distintas? Encontros e desencontros. Na Faculdade de Educação alguma discussão das relações de gênero e sexualidades. Como se essas questões fossem exclusivamente da escola. Como se educação fosse exclusivamente da escola. Como se fosse atribuição exclusiva da “formação pedagógica” discutir essas 
questões. Como abismos entre os conteúdos de História e o ensino de História? Abismos entre a formação em História e as relações de gênero e sexualidades? Formações que construam pontes, que possibilitem relações, aproximações, que possibilitem contemplar os abismos e problematizá-los. Pensar, a partir das escritas das/os estudantes, que relações de gênero e sexualidades são construídas na História, pela História, atravessam os conteúdos de História e podem ser categorias úteis de análise histórica, como aponta Scott (1995).

Nas últimas décadas, tem havido um maior investimento na formação docente inicial e continuada - para as temáticas de relações de gênero e sexualidades. Desde documentos como os Parâmetros Curriculares Nacionais até as proposições apontadas em diretrizes da Secretaria de Políticas para as Mulheres e de Direitos Humanos, passando por programas como o "Brasil sem Homofobia" e o curso "Gênero e Diversidade na Escola" (GDE), a visibilidade das questões concernentes aos processos políticos de reconhecimento das identidades e dos direitos fundamentais de mulheres e da população LGBTTI, produzem demandas para as escolas e para a formação docente. As Diretrizes Curriculares Nacionais para a Educação Básica (BRASIL, 2013) apontam sexualidade e gênero como temas abrangentes e contemporâneos, que devem ser articulados aos componentes curriculares, uma vez que afetam a vida social global, regional e local. Essa movimentação no campo da educação se articula com as demandas e reivindicações dos movimentos sociais feministas, de mulheres e LGBTTI, e com a intensa produção acadêmica, a partir das atividades de ensino, pesquisa e extensão desenvolvidas nas universidades. Destacam-se as disciplinas específicas que promovem formação docente inicial nos cursos de Licenciatura para as temáticas das relações de gênero e sexualidades e projetos de extensão que articulam as pesquisas realizadas com os cotidianos escolares.

As escritas das/os estudantes apontam para um processo que vem sendo vivido mais intensamente em algumas instituições, quando as relações de gênero e sexualidades passam a ser abordadas nas disciplinas de formação pedagógica. Mais do que ensinar modos de abordar essas temáticas nas escolas, esse trabalho pode investir na problematização de si e do mundo. Nesse sentido, as/os estudantes em formação terão oportunidade de pensar as instâncias de subjetivação que produzem modos de pensar, 
agir e sentir sobre as sexualidades e gêneros, tais como a educação familiar e escolar, os artefatos culturais - programas de TV, filmes, músicas, brinquedos, jogos eletrônicos, livros, imagens, obras de arte, sites da Internet, entre outros. Com essa abordagem, as/os estudantes poderão colocar sob suspeita seus conhecimentos e seus posicionamentos diante das sexualidades e gêneros, de modo a constituir uma ética de atuação docente que seja articuladora dos sujeitos escolares, de suas realidades e identidades.

\section{Referências}

ARROYO, Miguel G. Ofício de mestre: imagens e auto-imagens. 2 ed. Petrópolis, RJ: Vozes, 2000.

BRASIL. Ministério da Educação. Secretaria de Educação Básica. Diretrizes Curriculares Nacionais Gerais da Educação Básica. Brasília: MEC/SEB, DICEI, 2013.

COSTA, Aryana Lima; OLIVEIRA, Margarida Maria Dias de. O ensino de história como objeto de pesquisa no Brasil: no aniversário de 50 anos de uma área de pesquisa, notícias do que virá. SAECULUM - Revista de História, João Pessoa, n. 16, p. 147-160, jan./jun. 2007.

DIKOVISTSKAYA, Margaret. Visual culture: the study of the visual after the cultural turn. Cambridge: MIT Press, 2005.

FOUCAULT. Michel. História da sexualidade I: a vontade de saber. Rio de Janeiro: Edições Graal, 1988.

FOUCAULT. Michel. Microfísica do poder. Rio de Janeiro: Edições Graal, 1998. 
FURLANI, Jimena. Educação sexual na sala de aula: relações de gênero, orientação sexual e igualdade étnico-racial numa proposta de respeito às diferenças. Belo Horizonte: Autêntica, 2007.

HERNÁNDEZ, Fernando. Catadores da cultura visual: transformando fragmentos em nova narrativa educacional. Porto Alegre: Mediação, 2007.

LOURO, Guacira L. Gênero, sexualidade e educação: uma perspectiva pós-estruturalista. 8. ed. Petrópolis, RJ: Vozes, 2007.

MARSHALL, James D. Michel Foucault: pesquisa educacional como problematização. In: PETERS, Michael A.; BESLEY, Tina (Orgs.). Por que Foucault? Novas diretrizes para a pesquisa educacional. Porto Alegre: Artmed, 2008. p. 25-39.

SCOTT, Joan. Gênero: uma categoria útil de análise histórica. Educação \& Realidade, Porto Alegre, v. 2, n. 20, p. 71-99, jul./dez. 1995.

TARDIF, Maurice. Saberes profissionais dos professores e conhecimentos universitários. Revista Brasileira de Educação, Petrópolis, n.13, p.5-24, 2000. 